\title{
Ultra-High and Near-Zero Refractive Indices of Magnetron Sputtered Thin-Film Metamaterials Based on $\mathrm{Ti}_{x} \mathrm{O}_{y}$
}

\author{
Vukoman Jokanović, ${ }^{1,2}$ Božana Čolović, ${ }^{1}$ Miloš Nenadović, ${ }^{1}$ Anka Trajkovska Petkoska, ${ }^{3}$ \\ Miodrag Mitrić, ${ }^{1}$ Bojan Jokanović, ${ }^{4}$ and Ilija Nasov ${ }^{5}$ \\ ${ }^{1}$ Vinča Institute of Nuclear Sciences, University of Belgrade, Mike Petrovića Alasa 12-14, 11001 Belgrade, Serbia \\ ${ }^{2}$ ALBOS d.o.o., Orahovačka 19, 11000 Belgrade, Serbia \\ ${ }^{3}$ Faculty of Technology and Technical Sciences, University St. Kliment Ohridski, 1400 Veles, Macedonia \\ ${ }^{4}$ GL Group, Werner-von-Siemens-Straße, 86405 Meitingen, Germany \\ ${ }^{5}$ Plasma Doo, 29 November 66/9, 1000 Skopje, Macedonia
}

Correspondence should be addressed to Vukoman Jokanović; vukoman@vinca.rs

Received 30 November 2015; Accepted 28 March 2016

Academic Editor: Somchai Thongtem

Copyright (C) 2016 Vukoman Jokanović et al. This is an open access article distributed under the Creative Commons Attribution License, which permits unrestricted use, distribution, and reproduction in any medium, provided the original work is properly cited.

\begin{abstract}
Metamaterials based on $\mathrm{Ti}_{x} \mathrm{O}_{y}$ with ultra-high and near-zero refractive indices were obtained by DC magnetron sputtering. The data on refractive indices, extinction coefficients, film thickness, and band gaps, obtained by spectroscopic ellipsometry, showed very high potential of these materials as metamaterials. Phase analysis performed by XRD revealed the presence of titanium phases with lower titanium oxidation states resulting from high concentration of oxygen vacancies, which are crucial for such extraordinary jumps and drops of refractive indices. Numerous band gaps for direct and indirect electron transitions additionally confirmed unique properties of these materials.
\end{abstract}

\section{Introduction}

Thin titanium oxide films can be prepared by various routes, but direct current magnetron (DC) reactive sputtering is one of the most promising methods, because it allows control of the deposited film stoichiometry. High density, excellent adhesion, high hardness, and good thickness uniformity in large-area thin films can be also achieved [1-3]. A metal target can be used and a high deposition rate is achievable as well. This technique is widely applied to deposit hard, wearresistant, low friction, corrosion resistant, and decorative coatings, as well as coatings with specific optical or electrical properties [4-6]. It is especially useful for deposition of high-quality titanium dioxide $\left(\mathrm{TiO}_{2}\right)$ films at relatively low temperature $[7,8]$. Additionally, as-prepared $\mathrm{TiO}_{2}$ films show excellent electrical and optical properties such as high refractive index, dielectric constant, and visible light transmission, as well as strong mechanical and chemical stability, and good insulating properties $[9,10]$. High refractive indices result from special phase composition and structure of the films deposited by this method, while the higher optical band gap values can be attributed to the lattice distortion. This high refractive index in the visible and the near-infrared region makes them suitable for electrooptical devices, sensors, and optical coatings and as photocatalysts for oxidation of organic compounds $[3,11]$. The thin $\mathrm{Ti}_{x} \mathrm{O}_{y}$ films obtained by DC magnetron sputtering, presented in this paper, showed extraordinary optical properties (ultra-high and near-zero refractive index), which classify them as metamaterials. The obtained values are two times higher or several times lower (depending on the wavelength) than the typical ones for this system found in the literature. Physical properties of these materials make them suitable for a wide range of various applications such as in microstrip technology, beam self-collimation, strong field enhancement, optical links in lumped nanophotonic circuits, biomolecular sensors, fabrication of adaptive selective lenses, tunable mirrors, isolators, converters, and optical polarizers [12-14]. 


\section{Materials and Methods}

$\mathrm{Ti}_{x} \mathrm{O}_{y}$ thin films were deposited on glass slides $(2.5 \times 2.5 \mathrm{~mm})$ using a JCK-500A DC magnetron sputtering system. Previously, the substrate surface was prepared by etching of $\mathrm{SiO}_{2}$ layer in an ECR plasma etcher using $\mathrm{CF}_{4}$ as an etching gas at ambient temperature. The etching conditions were $0.02 \mathrm{~Pa}$ gas pressure, $400 \mathrm{~W}$ microwave power, $500 \mathrm{~V}$ accelerating electrode voltage, and $200 \mathrm{~mm}$ gap distance between the electrodes. Prior to the introduction of the sputtering gas, vacuum in the chamber was adjusted to $4 \times 10^{-4} \mathrm{mbar}$. Sputtering pressure was kept at $6 \times 10^{-1} \mathrm{mbar}$. The flow rates of Ar (99.999\%) and $\mathrm{O}_{2}(99.999 \%)$ were kept constant at 44.9 and $10 \mathrm{sccm}$ (standard cubic centimeter per minute), respectively. The discharges were generated at a constant power of $300 \mathrm{~W}$. The substrate temperature was maintained at $200^{\circ} \mathrm{C}$ and the deposition rate at about $4 \mathrm{~nm} / \mathrm{min}$. Thin films of samples 1 and 2 were deposited for 45 minutes and those of sample 3 for 7 minutes. Samples 2 and 3 were additionally thermally treated at $400^{\circ} \mathrm{C}$.

Phase composition of the samples (their appearance is shown in Appendix A) was analyzed by XRD (Philips PW 1051 Powder Diffractometer using Ni-filtered $\mathrm{Cu} \mathrm{K \alpha}$ radiation) and FTIR (Nicolet IS 50 FTIR Spectrometer). The morphology of thin films was investigated by SEM (SEM JEOL 5300). EDS (energy dispersive analysis) measurements were performed in order to determine the ratio between titanium and oxygen.

Spectroscopic ellipsometry was used for an additional characterization of $\mathrm{Ti}_{x} \mathrm{O}_{y}$ thin films deposited onto glass substrate [13]. For these measurements a HORIBA Jobin Yvon UVISEL iHR320 was used with the monochromator wavelength ranging from 200 to $2200 \mathrm{~nm}$ ( 0.6 up to $4.8 \mathrm{eV}$ ). Refractive index and extinction coefficient were determined as a function of wavelength. The incident angle was set at $70.1^{\circ}$ and the light spot was $1 \mathrm{~mm}$ in diameter. All optical spectra were recorded ex situ, with an energy step of $0.1 \mathrm{eV}$. Further analysis of the obtained optical spectra was performed by fitting the experimental data using a commercial software package DeltaPsi 2 (see Appendix B).

\section{Results}

3.1. Phase Analysis. As shown in Figure 1, the sample without additional thermal treatment 1 shows planes characteristic of TiO: (011), (031), and (-211) at 23.35, 37.24, and $37.43^{\circ}$, respectively. Also, anatase can be identified by a small peak corresponding to (101) plane observed at $24.87^{\circ}$ and a peak at $37.82^{\circ}$ corresponding to the (004) plane. For sample 2, (101), (004), and (113) planes at 25.36, 37.82, and $38.67^{\circ}$, respectively, can be attributed to anatase, while the (101) plane at $35.99^{\circ}$ corresponds to rutile and the $(-211)$ plane at $37.14^{\circ}$ to $\mathrm{TiO}$. Finally, sample 3 shows planes characteristic of anatase: (101), (004), and (112) at $25.27,37.72$, and $38.58^{\circ}$, respectively, as well as of rutile: (101) and (200) at 36.08 and $39.15^{\circ}$, respectively. Minor rutile phase is noticed in sample 2 while in sample 3 it is the major phase, confirming that the process of recrystallization inside of the system took place during additional thermal treatment of samples.
TABLE 1: Phase composition of the deposited thin $\mathrm{Ti}_{x} \mathrm{O}_{y}$ films.

\begin{tabular}{lcc}
\hline Sample & \multicolumn{2}{c}{ Phase composition, \% } \\
& $\mathrm{TiO}_{2}$ & $\mathrm{TiO}$ \\
\hline 1 & 84 & 16 \\
2 & 83 & 17 \\
3 & 90 & 10 \\
\hline
\end{tabular}

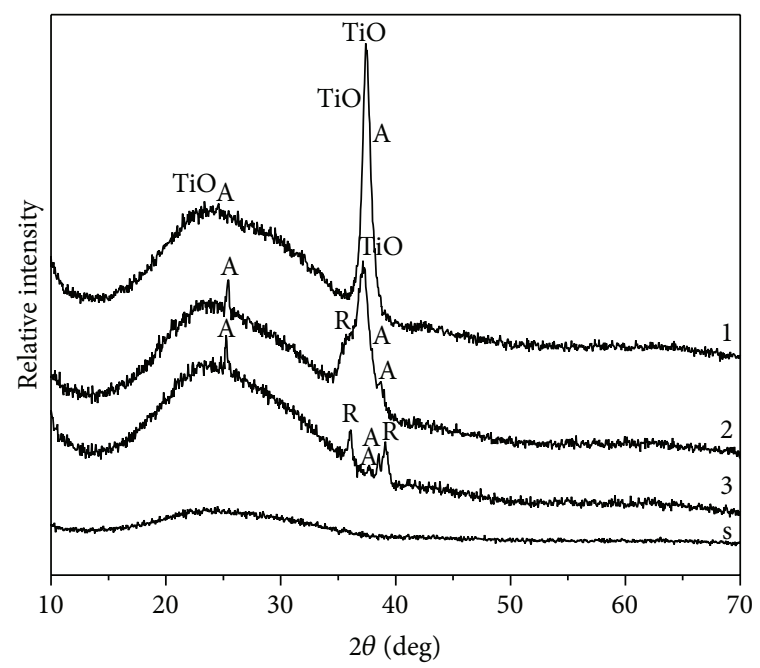

FIGURE 1: XRD patterns for $\mathrm{Ti}_{x} \mathrm{O}_{y}$ films obtained by DC magnetron sputtering (A: anatase, R: rutile, s: substrate, 1: sample deposited for $45 \mathrm{~min}$ and not further thermally treated, 2: sample deposited for $45 \mathrm{~min}$ and thermally treated at $400^{\circ} \mathrm{C}$, and 3: sample deposited for 7 min and thermally treated at $400^{\circ} \mathrm{C}$ ).

As it is obvious from Figure 1, shapes and maxima of the broad peaks at the diffraction angle $2 \theta$ between 15 and $30^{\circ}$ are more pronounced for samples 1, 2, and 3 than for amorphous $\mathrm{SiO}_{2}$ substrate, indicating that the amorphous phase of $\mathrm{Ti}_{x} \mathrm{O}_{y}$ is the prevailing titanium phase. The crystallite sizes, calculated using the Scherer equation, are in the range 7$25 \mathrm{~nm}$.

For a better insight into the structure of amorphous $\mathrm{Ti}_{x} \mathrm{O}_{y}$, the first coordination sphere radius $r$ was calculated using the well-known formula $2 r \sin \theta=1.23 \lambda$, where $\theta$ is the scattering angle and $\lambda$ is the $\mathrm{X}$-ray diffraction wavelength [14]. The obtained value of $0.224 \mathrm{~nm}$ was used for determination of the bond length and comparison with the theoretical bond length of anatase $[15,16]$. From these data, the chemical formula of the amorphous $\mathrm{Ti}_{x} \mathrm{O}_{y}$ phase was found to be $\mathrm{TiO}_{1.8}$. This indicates that the amorphous phase consists of ordered clusters with at least five interconnected subclusters of $\mathrm{TiO}_{1.8}$.

The quantitative phase composition of $\mathrm{Ti}_{x} \mathrm{O}_{y}$ thin films, determined by spectroscopic ellipsometry and using DeltaPsi 2 software package (see Appendix B), is shown in Table 1. The obtained data are in fair agreement with the data obtained by XRD.

EDS measurements (typical spot is shown in Appendix C) confirmed findings of XRD and spectroscopic ellipsometry. It was found that the ratio between titanium and oxygen is from $1: 1.75$ to $1: 1.9$. 


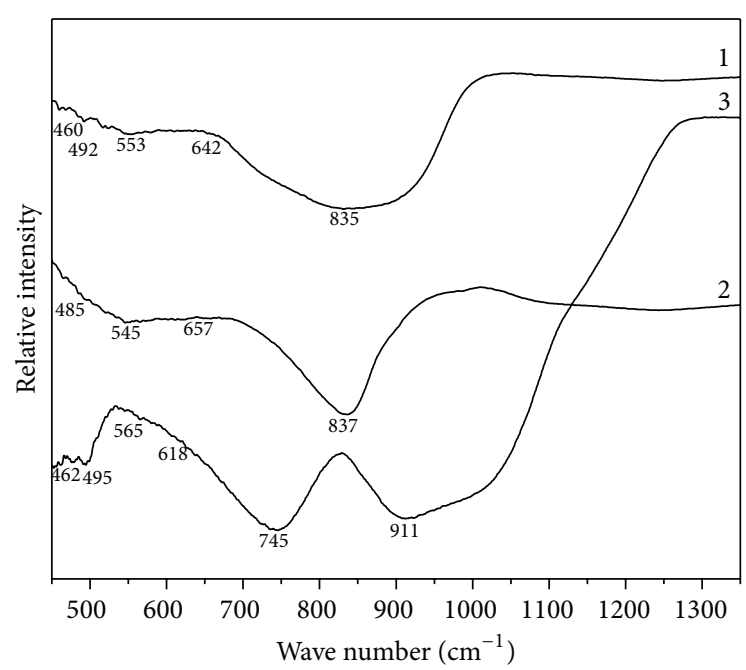

FIgURE 2: FTIR spectra of $\operatorname{Ti}_{x} \mathrm{O}_{y}$ films obtained by DC magnetron sputtering (1: sample deposited during $45 \mathrm{~min}$ without additional thermal treatment, 2: sample 1 thermally treated at $400^{\circ} \mathrm{C}$, and 3 : sample deposited during $7 \mathrm{~min}$ and thermally treated at $400^{\circ} \mathrm{C}$ ).

3.2. FTIR Analysis. FTIR spectra of $\mathrm{Ti}_{x} \mathrm{O}_{y}$ films obtained by magnetron sputtering are shown in Figure 2. The band at $835 \mathrm{~cm}^{-1}$ (sample 1) corresponds to the O-O stretching vibration inside $\mathrm{TiOOH}$. The bands between 660 and $600 \mathrm{~cm}^{-1}$ for samples 1-3 tail up to almost $900 \mathrm{~cm}^{-1}$ and can be assigned to $\mathrm{Ti}-\mathrm{O}$ stretching vibrations of $\mathrm{Ti}$ atoms in octahedral (near $600 \mathrm{~cm}^{-1}$ ) and tetrahedral (near $800-900 \mathrm{~cm}^{-1}$ ) surroundings or to stretching vibrations of $\mathrm{Ti}-\mathrm{O}-\mathrm{Ti}$ bonds in polytitanates. The peaks at $665-657 \mathrm{~cm}^{-1} \mathrm{can}$ be assigned also to surface phonon splitting of the vibration corresponding to small particle size anatase phase. The peaks at 520$579 \mathrm{~cm}^{-1}$ and broad and strongly pronounced peaks at 745 $735 \mathrm{~cm}^{-1}$ belong to $\mathrm{Ti}-\mathrm{O}$ and Ti-O-Ti stretching vibrations of anatase (sample 3). The pronounced splitting of the band at about $745-731 \mathrm{~cm}^{-1}$ may be induced by the various oxidative states of $\mathrm{Ti}$ in $\mathrm{TiO}_{2}$ and $\mathrm{TiO}$. The bands at 523-517 (band at $517 \mathrm{~cm}^{-1}$ corresponds to rutile phase) are connected with the absorption of Ti-O bonds present in stoichiometric titanium dioxide. Ratio between surfaces of bands at $523-502 \mathrm{~cm}^{-1}$ and bands at $765-751 \mathrm{~cm}^{-1}$ shows ration between $\mathrm{Ti}-\mathrm{O}$ and $\mathrm{T}=\mathrm{O}$, oxides and suboxides. Besides, all peaks between 506 and $565 \mathrm{~cm}^{-1}$ correspond to octahedral surroundings of the titanium atoms in the coatings, while the bands at $492-468 \mathrm{~cm}^{-1}$ may correspond to the TP phonon frequency of $\mathrm{TiO}_{2}$ in the rutile phase, and the bands at $468-453 \mathrm{~cm}^{-1}$ can be assigned to vibrations of $\mathrm{TiO}_{6}$ octahedron, related to $\mathrm{Ti}-\mathrm{O}$ stretching bonds directed either to the interlayer space or to the outer surface formed nanotube, while $434-406 \mathrm{~cm}^{-1}$ bands (samples 2 and 3) correspond to the TP phonon frequency of nanocrystalline $\mathrm{TiO}_{2}$ phase anatase or rutile phase.

3.3. Film Morphology. At a magnification of 200,000x, SEM images show almost flat surface with barely visible surface patterns (Figure 3). This indicates the epitaxial growth of titanium oxide film formed layer by layer on the substrate
TABLE 2: The band gap energies of samples and the corresponding wavelengths.

\begin{tabular}{ccccc}
\hline \multirow{2}{*}{ Sample } & \multicolumn{2}{c}{ Direct transition } & \multicolumn{2}{c}{ Indirect transition } \\
& $E_{g}, \mathrm{eV}$ & $\lambda$ range, $\mathrm{nm}$ & $E_{g}, \mathrm{eV}$ & $\lambda$ range, $\mathrm{nm}$ \\
\hline \multirow{3}{*}{1} & 1.05 & $729-960$ & 1.10 & $945-1050$ \\
& 1.97 & $530-588$ & 2.05 & $563-590$ \\
& 3.00 & $386-400$ & 3.00 & $382-405$ \\
& 3.71 & $318-326$ & 3.57 & $318-326$ \\
\hline \multirow{3}{*}{2} & 0.85 & $867-1087$ & 0.97 & $1127-1228$ \\
& 1.73 & $650-688$ & 1.78 & $650-688$ \\
& 2.61 & $427-460$ & 2.57 & $457-478$ \\
& 3.08 & $386-400$ & 3.09 & $387-401$ \\
& 3.56 & $272-336$ & 3.43 & $317-336$ \\
\hline \multirow{3}{*}{3} & 2.68 & $387-406$ & 1.19 & $652-775$ \\
& 3.21 & $344-366$ & 1.77 & $471-516$ \\
& 3.33 & $274-322$ & 2.75 & $392-413$ \\
& 4.39 & $258-263$ & 3.17 & $352-365$ \\
\hline
\end{tabular}

surface. Slight surface roughness observed in SEM micrographs probably results from partially shifted neighbor layers induced by the similar roughness of the substrate. The epitaxial growth of the prevailing amorphous $\mathrm{Ti}_{x} \mathrm{O}_{y}$ phase is supported by the amorphous silica phase of substrate because for epitaxial growth of high-quality films, it is desirable to have neglected lattice mismatch between film phases and the substrate.

Oxygen vacancies, uniformly distributed, are the main defects in the as-grown films. If present in higher concentrations they can coalesce to form pores, but the pores have not been noticed even at very high magnifications and thus the porosity of the films can be neglected.

Based on spectroscopic ellipsometry data, using software package DeltaPsi 2 (see Appendix B), $\mathrm{Ti}_{x} \mathrm{O}_{y}$ thin-film thicknesses were calculated to be $172 \pm 9,176 \pm 10$, and $29 \pm 3 \mathrm{~nm}$ for samples 1,2 , and 3 , respectively.

3.4. Band Gap Energy. The energy gaps $E_{g}$ for direct and indirect electron transitions from the valence to the conduction band were determined using the Tauc equation: $\alpha(h \nu)=$ $C\left(h v-E_{g}\right)^{a / 2} / h v$, where $\alpha$ is the absorption coefficient (derived from the extinction coefficient $k$ data: $\alpha=4 \pi k / \lambda$ ), $C$ is a constant, and $a=1$ for direct and $a=4$ for indirect transition [17]. The energy gap values, obtained by extrapolation of the linear part of plots $(\alpha h \nu)^{2 / a}$ versus $h v$ (see Appendix D), are given in Table 2 .

3.5. Refractive Indices. It can be noticed in Figure 4 that there are differences in refractive index values ranging from ultrahigh to near-zero ones, which is of great importance for the potential application of these materials. The highest values of refractive indices are 5.1 and 5.0 at 399.9 and $688.8 \mathrm{~nm}$ for sample 2 and 4.2 at $590.4 \mathrm{~nm}$ for sample 1, while the lowest, near-zero ones are 0.28 at $590.4 \mathrm{~nm}$ for sample 2 and 0.41 at $1377.6 \mathrm{~nm}$ for sample 1 . These values indicate that at certain wavelengths this material shows the properties typical 


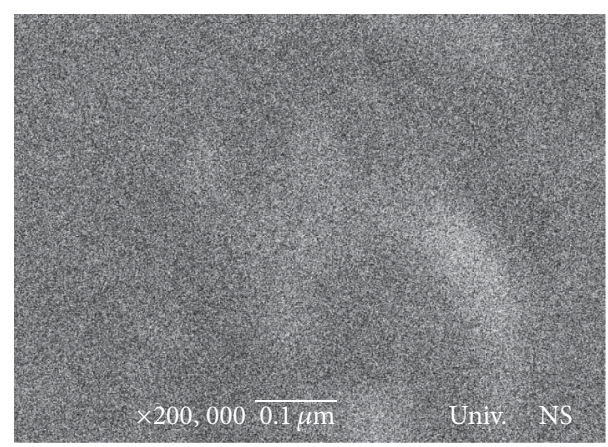

(a)

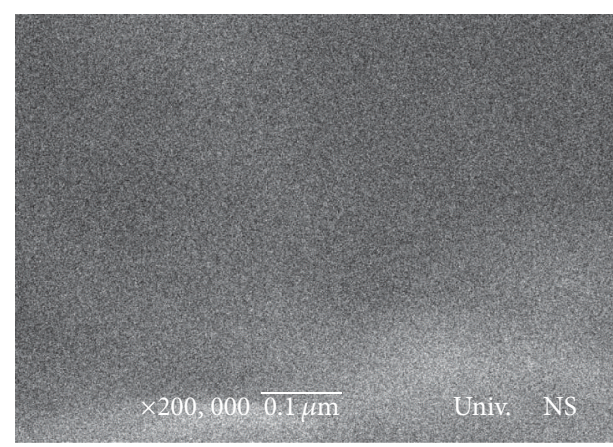

(b)

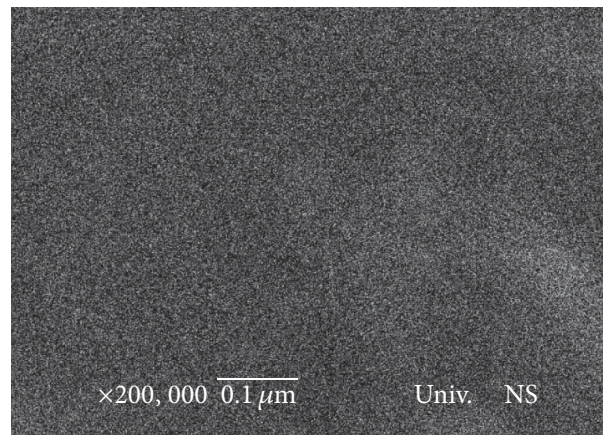

(c)

FIGURE 3: SEM micrographs of (a) sample 1, (b) sample 2, and (c) sample 3.

of metamaterials. Opposite to samples 1 and 2, sample 3 shows refractive indices in the range expected for anatase/rutile due to lower concentration of oxygen vacancies, that is, higher oxidation states of $\mathrm{Ti}$.

The extinction coefficient, as a measure of attenuation during the electromagnetic wave propagation through the material, shows slightly different behavior than refractive indices, with shifted maximums and minimums towards lower wavelength values.

\section{Discussion}

On the basis of phase analysis it is obvious that titanium is present in different oxidative states: $\mathrm{Ti}^{2+}(\mathrm{TiO}), \mathrm{Ti}^{3+}\left(\mathrm{Ti}_{2} \mathrm{O}_{3}\right)$, mixed $\mathrm{Ti}^{4+}$ and $\mathrm{Ti}^{3+}$ in ratio $1: 2\left(\mathrm{Ti}_{3} \mathrm{O}_{5}\right)$, and $\mathrm{Ti}^{4+}$ (anatase, rutile). In all $\mathrm{Ti}_{x} \mathrm{O}_{y}$, $\mathrm{Ti}$ is in octahedral coordination, surrounded by $6 \mathrm{O}$ atoms, while each $\mathrm{O}$ atom is surrounded by 3Ti atoms (except of $\mathrm{TiO}$ ). The site symmetry of $\mathrm{Ti}$ and $\mathrm{O}$ atoms in all of them differs [18].

In the rutile and anatase the site symmetry of $\mathrm{Ti}$ is $\mathrm{D}_{2 \mathrm{~h}}$. The elongation of $\mathrm{O}-\mathrm{Ti}-\mathrm{O}$ bonds along the $z$ direction of the coordination polyhedron and deviation of the angles from $90^{\circ}$ lead to a decrease in symmetry from octahedral to tetragonal $\mathrm{D}_{2 \mathrm{~h}}$ symmetry. In $\mathrm{Ti}_{2} \mathrm{O}_{3}$ the site symmetry of $\mathrm{Ti}$ is $\mathrm{C}_{3 \mathrm{i}}$, which leads to the distortion of the coordination polyhedra from octahedral to trigonal symmetry. In $\mathrm{Ti}_{3} \mathrm{O}_{5}$ the symmetry of both $\mathrm{Ti}$ and $\mathrm{O}$ atoms is $\mathrm{C}_{\mathrm{s}}$ [18].

For each of these phases, the distortion of molecular orbitals occurs due to different symmetry sites of $\mathrm{Ti}$ and
$\mathrm{O}$ atoms. This influences the splitting of Ti d orbitals into triply degenerated $t_{2 \mathrm{~g}}$ band consisting of $d_{x y}, d_{x z}$, and $d_{y z}$ orbitals (higher energy state) and doubly degenerated $\mathrm{e}_{\mathrm{g}}$ band consisting of $d_{x^{2}-y^{2}}$ and $d_{z^{2}}$ orbitals (lower energy state). $\mathrm{e}_{\mathrm{g}}$ group has the proper symmetry to interact with the oxygen orbitals, forming sigma bonding $(\sigma)$ and antibonding $\left(\sigma^{*}\right)$ molecular orbitals (MO): $3 \mathrm{e}_{\mathrm{g}}\left(\sigma^{*}\right)$ in interaction with $\mathrm{O} 2 \mathrm{p}$ $\sigma$ orbitals and $2 \mathrm{e}_{\mathrm{g}}(\sigma)$ and $1 \mathrm{e}_{\mathrm{g}}(\sigma)$ in interaction with $\mathrm{O} 2 \mathrm{~s}$ orbitals. $t_{2 g}$ orbitals form pi bonding $(\pi)$ and antibonding $\left(\pi^{*}\right)$ orbitals: $2 \mathrm{t}_{2 \mathrm{~g}}\left(\pi^{*}\right)$ and $1 \mathrm{t}_{2 \mathrm{~g}}(\pi)$ in interaction with $\mathrm{O} 2 \mathrm{p} \pi$ orbitals. Besides, in the interaction of $\mathrm{Ti} 4 \mathrm{~s}$ and $\mathrm{O} 2 \mathrm{~s}$ orbitals, $2 \mathrm{a}_{1 \mathrm{~g}}(\sigma)$ and $1 \mathrm{a}_{1 \mathrm{~g}}(\sigma) \mathrm{MO}$ are formed and $3 \mathrm{a}_{1 \mathrm{~g}}\left(\sigma^{*}\right)$ MO is formed in interaction of $\mathrm{Ti} 4 \mathrm{~s}$ and $\mathrm{O} 2 \mathrm{p} \sigma$ orbitals. In the interaction of $\mathrm{Ti} 4 \mathrm{p}$ and $\mathrm{O} 2 \mathrm{~s}$ orbitals, $2 \mathrm{t}_{1 \mathrm{u}}(\sigma)$ and $1 \mathrm{t}_{1 \mathrm{u}}(\sigma)$ $\mathrm{MO}$ are formed, while in the interaction of $\mathrm{Ti} 4 \mathrm{p}$ and $\mathrm{O} 2 \mathrm{p}$ orbitals $4 \mathrm{t}_{1 \mathrm{u}}\left(\sigma, \pi^{*}\right)$ and nonbonding $\mathrm{t}_{1 \mathrm{~g}}\left(\pi^{0}\right)$ and $\mathrm{t}_{2 \mathrm{u}}\left(\pi^{0}\right)$ $\mathrm{MO}$ orbitals are formed. All antibonding orbitals are empty except $2 \mathrm{t}_{2 \mathrm{~g}}\left(\pi^{*}\right)$ on the bottom of conduction band, which are partially filled in the case of $\mathrm{Ti}_{2} \mathrm{O}_{3}$ and $\mathrm{Ti}_{3} \mathrm{O}_{5}$ (having 1 electron) and $\mathrm{TiO}$ (having 2 electrons). $\mathrm{O} 2 \mathrm{p}$ states with nonbonding orbitals $\left(t_{1 g}\left(\pi^{0}\right)\right.$ and $\left.t_{2 u}\left(\pi^{0}\right)\right)$ at the highest energy level occupy the top of the valence band [18-20].

As a result of influence of distorted octahedral crystal fields in various $\mathrm{Ti}_{x} \mathrm{O}_{y}$, splitting and rearrangement of energy sublevels in $\mathrm{e}_{\mathrm{g}}$ and $\mathrm{t}_{2 \mathrm{~g}}$ groups of orbitals in the conduction band occur. For $\mathrm{TiO}, \mathrm{Ti}_{2} \mathrm{O}_{3}$, and $\mathrm{Ti}_{3} \mathrm{O}_{5}$, high concentration of oxygen vacancies results in an additional splitting of $t_{2 g}$ orbitals in valence band (near the Fermi level). Therefore, the lowest values of band gaps $(0.85 \mathrm{eV}$ to $1.97 \mathrm{eV})$ probably 


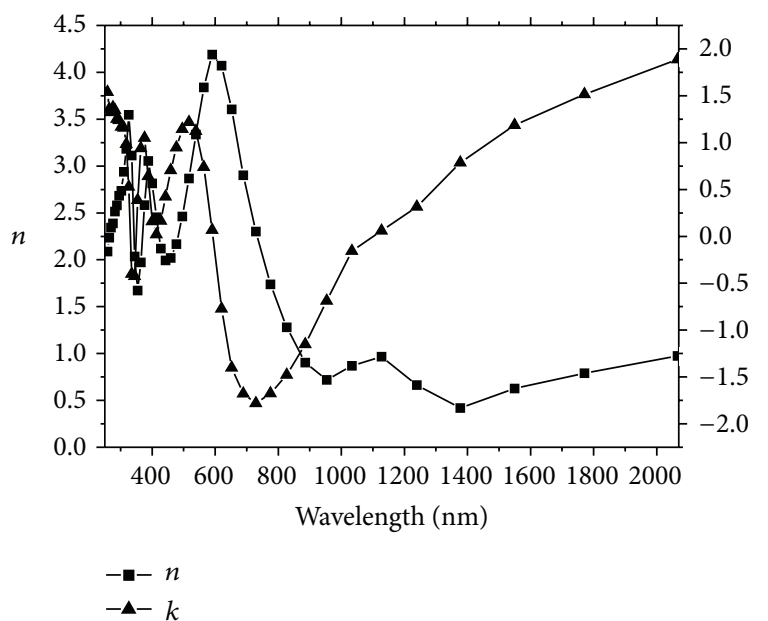

(a)

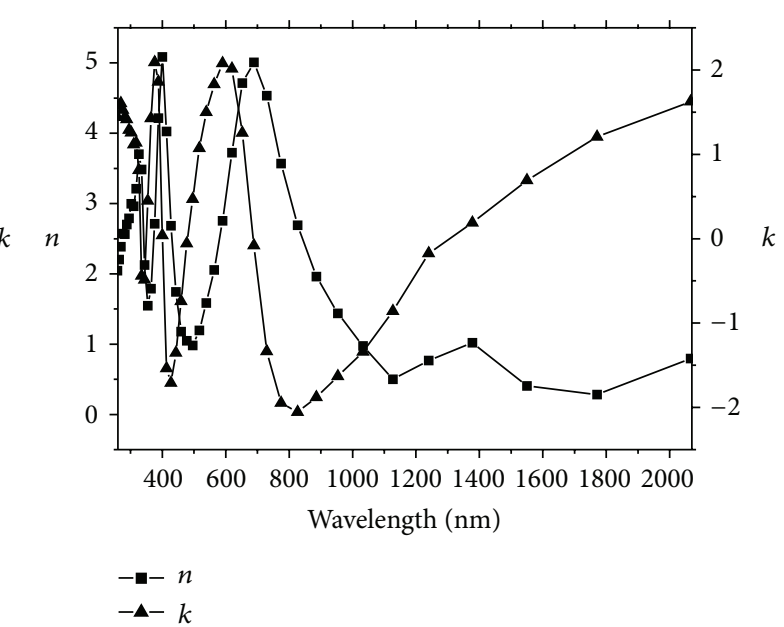

(b)

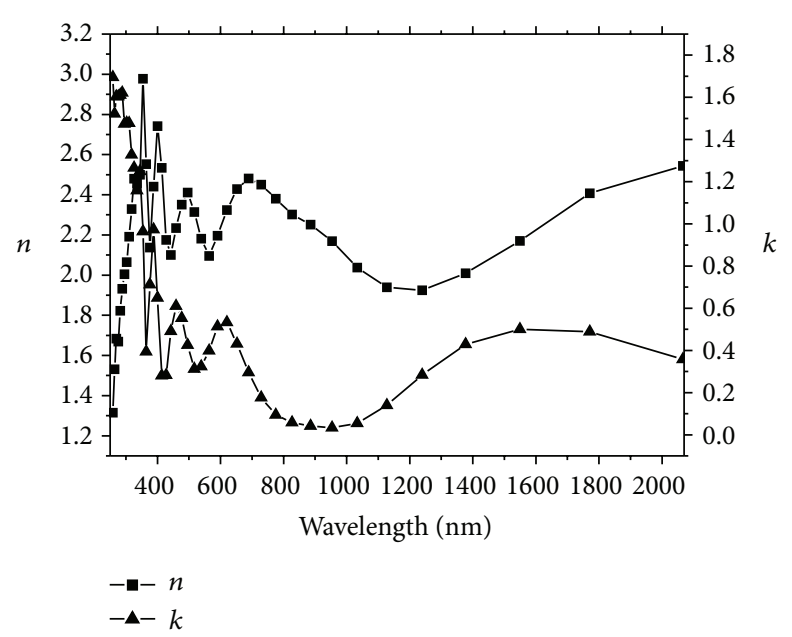

(c)

FIgURE 4: Refractive index $(n)$ and extinction coefficient $(k)$ versus wavelength: (a) sample 1, (b) sample 2, and (c) sample 3.

belong to the transition from the highest occupied molecular orbitals (HOMO), mainly $\mathrm{O} 2 \mathrm{p}$ orbitals, corresponding to the valence band to the lowest unoccupied $\mathrm{Ti} 3 \mathrm{~d}$ orbitals corresponding to the conduction band [21]. These low values of band gaps show that these phases exhibit metal (TiO) and semiconductive $\left(\mathrm{Ti}_{2} \mathrm{O}_{3}\right.$ and $\left.\mathrm{Ti}_{3} \mathrm{O}_{5}\right)$ character and consequently their metamaterials behavior. The band gap values 2.61 and 2.68 probably belong to phases with Ti oxidative states between $\mathrm{Ti}^{3+}$ and $\mathrm{Ti}^{4+}$. For oxidative state $\mathrm{Ti}^{4+}$, it exhibits insulator characteristics (3.00-4.39 eV) [22].

Ultra-high and near-zero refractive indices of $\mathrm{Ti}_{x} \mathrm{O}_{y}$ samples 1 and 2 (characteristic for metamaterials) are the result of the previously explained electronic structure of metallic and semiconductive phases present in $\operatorname{Ti}_{x} \mathrm{O}_{y}$ films. Such high defect structure induces specific interactions between light electromagnetic waves (LEW) and plasmonic waves of free electrons in the conduction band and weakly bound electrons in valence band coupled with the $\operatorname{Ti}_{x} \mathrm{O}_{y}$ crystalline phases embedded in the matrix of amorphous phase. In a simplified model, $\mathrm{Ti}_{x} \mathrm{O}_{y}$ nanoparticles can be considered as a network of positive nuclei surrounded by freely oscillating electrons. In interaction with LEW, these electrons accumulate on one side of the nanoparticle surface, while the other remains positive. As-formed nanodipoles have the direction opposite to the electric field of light [23-25]. They then radiate their own waves, which combine with the incoming waves. The phase between the incoming and the induced waves determines whether the refractive index will be extremely high or close to zero. If the incoming wave oscillates relatively slowly, the electrons can follow the wave: they are in phase, because their oscillation frequency around some equilibrium position is in resonance with the incoming light wave and the refractive index is extremely high ( 4.2 for sample 1 and 5.1 for sample 2 ). In the case when the incoming wave frequency exceeds that of the free electrons or particularly electrons coupled with lattices of nanocrystallites and subnanocrystallites, the electrons can no longer follow the wave, and they get out of phase. Then, the waves radiated by the electrons are out of phase 
too, and the refractive index is close to zero ( 0.41 for sample 1 and 0.28 for sample 2) [26-30].

Considering high number of various direct and indirect electron transitions between the valence and the conduction band and inside the conduction band of $\mathrm{Ti}$ and $\mathrm{O}$ in samples 1 and 2 it is obvious that during the interaction of the samples with LEW an overlapping of the conduction and valence zones occurs, forming consequently a continuous range of energy states of electrons. Some of them will be in resonance with incident electromagnetic waves at lower wavelengths (showing extremely high refractive index), while the others will be in the opposite phase at higher light wavelengths (showing close to zero values of the refractive index).

Higher values of extinction coefficients are mainly caused by intraband transitions. They can also cause a significant change in phase angle of the plasmonic wave during the interference with incident LEW. Extinction coefficient is negative in the wavelength range of $619-1033 \mathrm{~nm}$ for sample 1 and $688-1240 \mathrm{~nm}$ for sample 2 . It is influenced by transfer of electrons from ground state to metastable excited state due to the energy of xenon light source during the ellipsometry measurements. Estimated amount of the energy added to the samples from the source, in area where the extinction coefficient is negative, is $1.1-1.9 \mathrm{eV}$ for sample 1 and $0.9-1.7 \mathrm{eV}$ for sample 2. This energy induces inverse occupation, that is, transfer of electrons to excited metastable state. Characteristics of the xenon source show that its highest intensity of radiation is in the range of $750-1000 \mathrm{~nm}$. Due to this, the number of electrons in excited metastable state is maximal in that range.

\section{Conclusions}

$\mathrm{Ti}_{x} \mathrm{O}_{y}$ thin films, thickness from 29 to $176 \mathrm{~nm}$, were obtained by DC magnetron sputtering. The films were mainly constituted of an amorphous phase and crystal phases of anatase, rutile, and TiO. Phase composition of the films proved by XRD and ellipsometry indicated high concentration of oxygen vacancies, which caused ultra-high and close to zero values of refractive indices. The highest value of the refractive index was 5.1 and the lowest 0.28 . The band gaps for direct and indirect transitions between the valence and the conduction band were in a wide range from 0.85 to $4.39 \mathrm{eV}$. The highest refractive index corresponds to the resonance of plasmonic waves of free electrons and incident electromagnetic waves, while the near-zero refractive index corresponds to the interference of plasmonic waves of electrons coupled with lattices of nanocrystals and subnanocrystals and incident electromagnetic waves.

\section{Appendix}

\section{A. Appearance of the Films}

$\mathrm{Ti}_{x} \mathrm{O}_{y}$ films of various thicknesses show different colors, depending on the film thickness and concentration of oxygen vacancies (Figure 5).

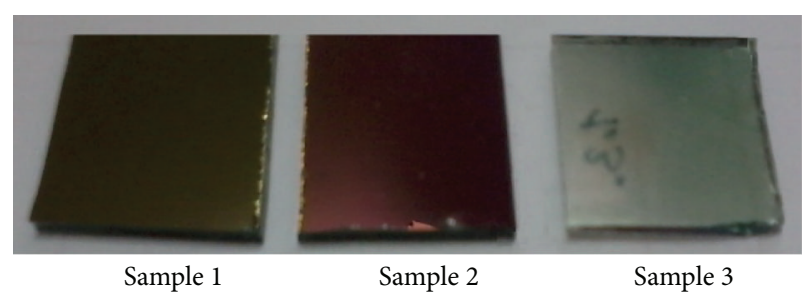

FIGURE 5: The appearance of $\mathrm{Ti}_{x} \mathrm{O}_{y}$ films.

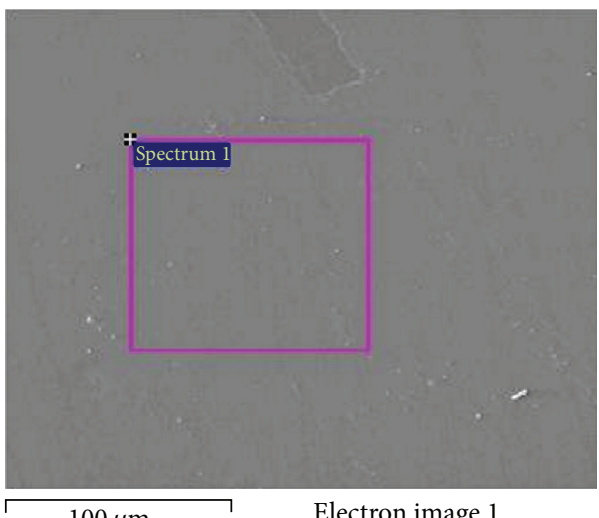

Figure 6

\section{B. Fitting Procedure of the Data Obtained by Spectroscopic Ellipsometry}

In a $\mathrm{Ti}_{x} \mathrm{O}_{y}$ system standard fit of Is and Ic signal intensities was used according to the following equations:

$$
\begin{aligned}
& I s=\sin (2 \Psi) \cdot \sin (\Delta), \\
& I c=\sin (2 \Psi) \cdot \cos (\Delta),
\end{aligned}
$$

where $\Psi$ is amplitude change of reflected wave, while $\Delta$ is a phase change of the same reflected light beam. Software package DeltaPsi 2 gives an explicit form depending on the refractive index and extinction coefficient of the wavelength.

Fitting the model to the experimental curve was estimated using the Levenberg-Marquardt algorithm, with the analytical parameters which are simultaneously determined through the iterative process change until the chi-squared function (B.2) obtains the minimum value:

$$
=\min \sum_{i=1}^{n}\left[\frac{\left(\Psi_{\text {teor }}-\Psi_{\text {eksp }}\right)_{i}^{2}}{\Gamma_{\Psi, i}}+\frac{\left(\Delta_{\text {teor }}-\Delta_{\text {eksp }}\right)_{i}^{2}}{\Gamma_{\Delta, i}}\right] .
$$

In the above expression, $n$ is the total number of recorded points $\left(\Psi_{\text {eksp }}, \Delta_{\text {eksp }}\right)$, while $\left(\Psi_{\text {teor }}, \Delta_{\text {teor }}\right)$ are experimental values of ellipsometric angles and corresponding values calculated from the model using a parameter $\Gamma_{\Delta, i}$ for calculation of experimental error. All calculations were performed using 

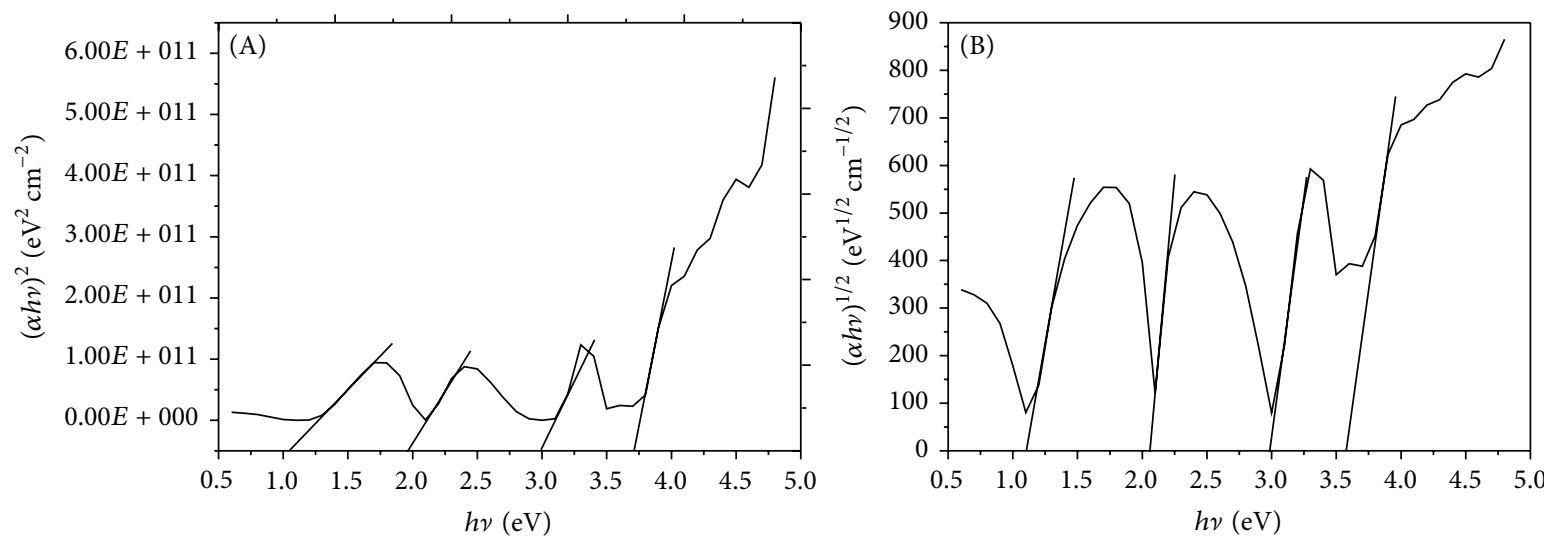

(a)
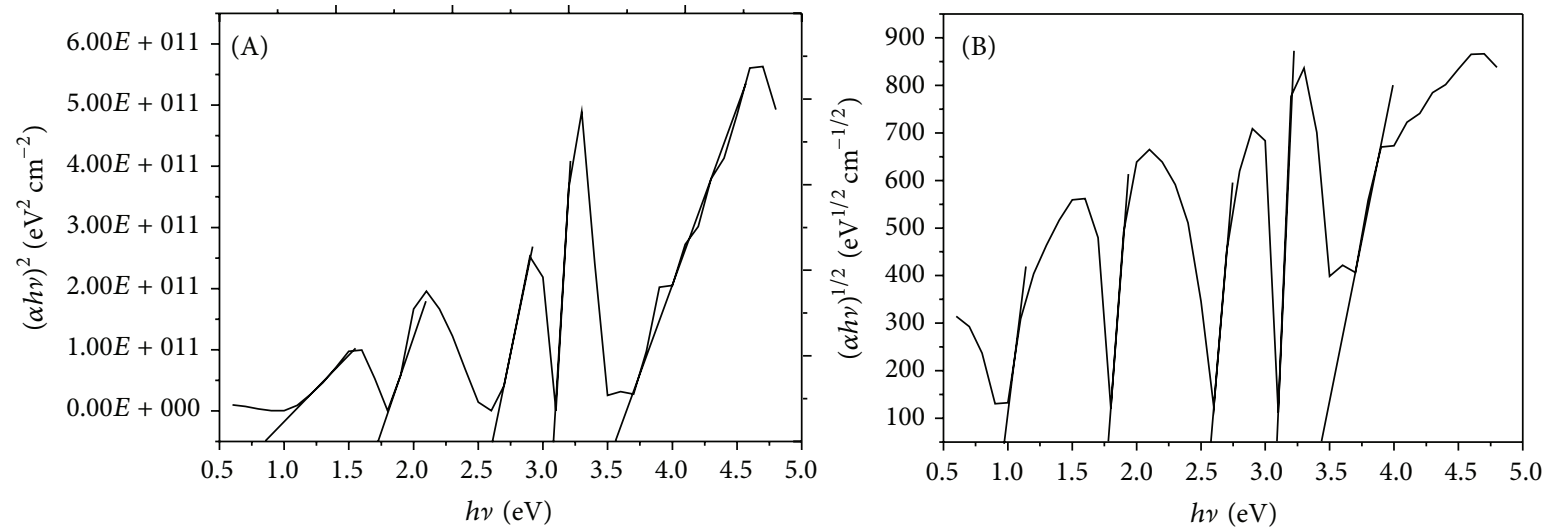

(b)
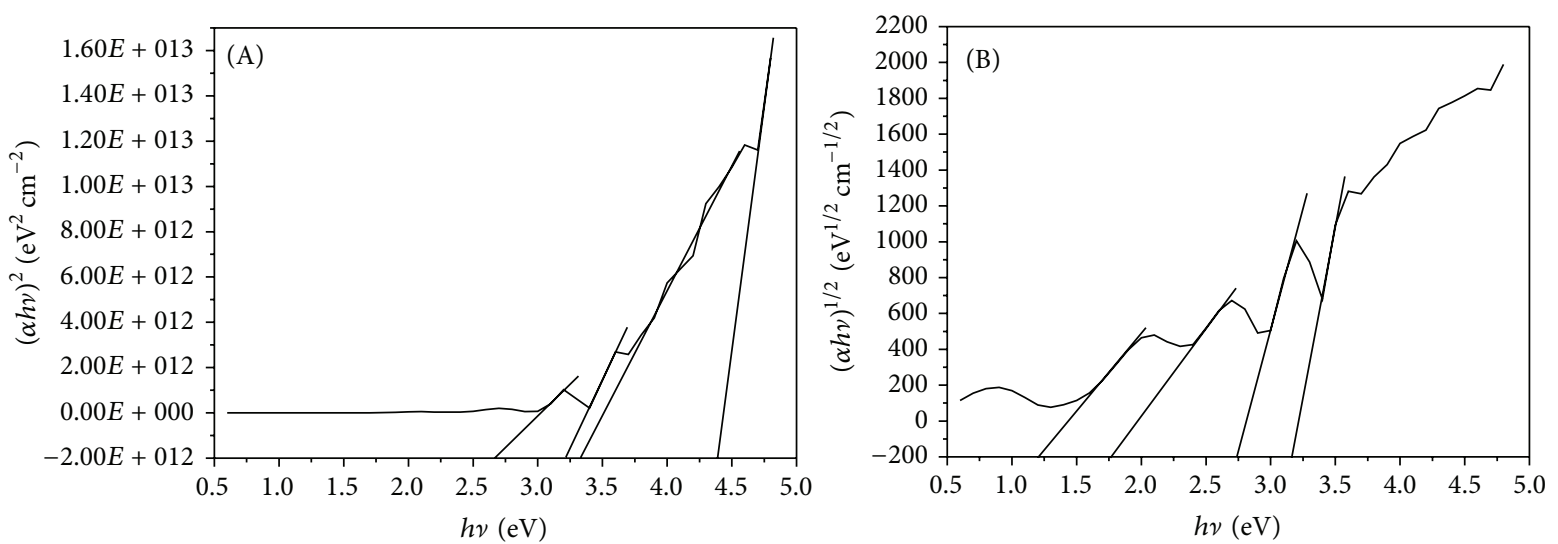

(c)

FIGURE 7: Dependence $(\alpha h \nu)^{2 / a}$ as a function of radiation energy $h v$ for (a) sample 1, (b) sample 2, and (c) sample 3 ((A) direct transition $(a=2)$ and (B) indirect transition $(a=4))$.

DeltaPsi 2 software package, which is an integral part of the device.

Data interpretation is very difficult from the absolute values of ellipsometric $(\Psi, \Delta)$ angles and it is necessary to create an appropriate optical model. In the case of thin layers of $\mathrm{TiO}_{2}$ fitting of the experimental data was carried out using a twolayer model: one homogeneous layer of $\mathrm{TiO}_{2}$ and a surface layer of several nanometers, with the composition of $50 \%$ $\mathrm{TiO}_{2}+50 \%$ voids, which describes the roughness of the sample.

To describe the properties of thin films of $\mathrm{TiO}_{2}$ new amorphous theoretical model was used, which is a modified Tauc-Lorentz model. This model is generally used to describe the dielectric that partially absorbs light (which absorbs light 
only in defined range of the wavelength) and in semiconductors. Extinction coefficient is given by

$$
\begin{aligned}
& k(\omega)=\frac{f_{j} \cdot\left(\omega-\omega_{g}\right)^{2}}{\left(\omega-\omega_{j}\right)^{2}+\Gamma_{j}^{2}} ; \quad \text { for } \omega>\omega_{g}, \\
& k(\omega)=0 ; \quad \text { for } \omega \leq \omega_{g},
\end{aligned}
$$

where the values $f$ and $\Gamma_{j}$ related to the height or width of the absorption maximum and $\omega_{j}$ represents the energy at which the extinction coefficient has a maximum value. Parameter $\omega_{g}$ represents value of the material energy gap and it is equal to the lowest value of the energy which is required for the transition from the valence into the guide zone.

The refractive index is expressed by the relation

$$
n(\omega)=n_{\infty}+\frac{B \cdot\left(\omega-\omega_{j}\right)+C}{\left(\omega-\omega_{j}\right)^{2}+\Gamma_{j}^{2}}
$$

where $B$ and $C$ are coefficients that depend on the fitting parameters $f, \Gamma_{j}, \omega_{j}$, and $\omega_{g}$. Value $n_{\infty}$ is an additional parameter that represents the index refraction value when $\omega \rightarrow \infty$.

\section{A Typical Spot for EDS Measurements}

See Figure 6.

\section{Determination of Band Gaps Energies from Diagrams $(\alpha h \nu)^{2 / a}$ versus $h v$}

See Figure 7.

\section{Competing Interests}

The authors declare that they have no competing interests.

\section{Acknowledgments}

This study was supported by the Ministry of Education, Science and Technological Development of the Republic of Serbia (Project no. 172026).

\section{References}

[1] J. O. Carneiro, V. Teixeira, A. J. Martins, M. Mendes, M. Ribeiro, and A. Vieira, "Surface properties of doped and undoped $\mathrm{TiO}_{2}$ thin films deposited by magnetron sputtering," Vacuum, vol. 83 , no. 10, pp. 1303-1306, 2009.

[2] M. Einollahzadeh-Samadi and R. S. Dariani, "Effect of substrate temperature and deposition rate on the morphology and optical properties of Ti films," Applied Surface Science, vol. 280, pp. 263267, 2013.

[3] M. Shirolkar, M. Kazemian Abyaneh, A. Singh et al., "Rapidly switched wettability of titania films deposited by dc magnetron sputtering," Journal of Physics D: Applied Physics, vol. 41, no. 15, Article ID 155308, 8 pages, 2008.

[4] J. Hernández-Torres, L. García-González, L. Zamora-Peredo et al., "Analysis of hardness of nanocrystalline coatings of aluminum-rich $\mathrm{Ti}_{1-x} \mathrm{Al}_{x} \mathrm{~N}$," Bulletin of Materials Science, vol. 35, no. 5, pp. 733-738, 2012.

[5] L. Jakab-Farkas, D. Biro, G. Strnad, and I. Vida-Simiti, "Preparation and characterization of $(\mathrm{Ti}, \mathrm{Al}, \mathrm{Si}) \mathrm{N}$ coatings developed by d.c. reactive magnetron sputtering," Journal of Optoelectronics and Advanced Materials, vol. 15, no. 7-8, pp. 696-702, 2013.

[6] J. Bhattarai, E. Akiyama, A. Kawashima, K. Asami, and K. Hashimoto, "The corrosion behavior of sputter-deposited amorphous W-Ti alloys in $6 \mathrm{M} \mathrm{HCl}$ solution," Corrosion Science, vol. 37, no. 12, pp. 2071-2086, 1995.

[7] M. Stamate, I. Vascan, I. Lazar, G. Lazar, I. Caraman, and M. Caraman, "Optical and surface properties $\mathrm{TiO}_{2}$ thin films deposited by DC magnetron sputtering method," Journal of Optoelectronics and Advanced Materials, vol. 7, no. 2, pp. 771774, 2005.

[8] P. Löbl, M. Huppertz, and D. Mergel, "Nucleation and growth in $\mathrm{TiO}_{2}$ films prepared by sputtering and evaporation," Thin Solid Films, vol. 251, no. 1, pp. 72-79, 1994.

[9] R. Wang, K. Hashimoto, A. Fujishima et al., "Light-induced amphiphilic surfaces," Nature, vol. 388, no. 6641, pp. 431-432, 1997.

[10] L. Miao, P. Jin, K. Kaneko, A. Terai, N. Nabatova-Gabain, and S. Tanemura, "Preparation and characterization of polycrystalline anatase and rutile $\mathrm{TiO}_{2}$ thin films by rf magnetron sputtering," Applied Surface Science, vol. 212-213, pp. 255-263, 2003.

[11] O. Carp, C. L. Huisman, and A. Reller, "Photoinduced reactivity of titanium dioxide," Progress in Solid State Chemistry, vol. 32, no. 1-2, pp. 33-177, 2004.

[12] V. Yannopapas and A. Moroz, "Negative refractive index metamaterials from inherently non-magnetic materials for deep infrared to terahertz frequency ranges," Journal of Physics Condensed Matter, vol. 17, no. 25, pp. 3717-3734, 2005.

[13] P. Moitra, Y. Yang, Z. Anderson, I. I. Kravchenko, D. P. Briggs, and J. Valentine, "Realization of an all-dielectric zero-index optical metamaterial," Nature Photonics, vol. 7, no. 10, pp. 791795, 2013.

[14] M. Choi, S. H. Lee, Y. Kim et al., "A terahertz metamaterial with unnaturally high refractive index," Nature, vol. 470, no. 7334, pp. 369-373, 2011.

[15] B. Prasai, B. Cai, M. K. Underwood, J. P. Lewis, and D. A. Drabold, "Properties of amorphous and crystalline titanium dioxide from first principles," Journal of Materials Science, vol. 47, no. 21, pp. 7515-7521, 2012.

[16] V. V. Hoang, H. Zung, and N. H. B. Trong, "Structural properties of amorphous $\mathrm{TiO}_{2}$ nanoparticles," European Physical Journal $D$, vol. 44, no. 3, pp. 515-524, 2007.

[17] P. Karasiński, E. Gondek, S. Drewniak, and I. V. Kityk, "Nanosized blue spectral shift in sol-gel derived mesoporous titania films," Journal of Sol-Gel Science and Technology, vol. 61, no. 2, pp. 355-361, 2012.

[18] E. Stoyanov, F. Langenhorst, and G. Steinle-Neumann, "The effect of valence state and site geometry on $\mathrm{Ti} \mathrm{L}_{3,2}$ and $\mathrm{O}$ $K$ electron energy-loss spectra of $\mathrm{Ti}_{x} \mathrm{O}_{y}$ phases," American Mineralogist, vol. 92, pp. 577-586, 2007.

[19] F. M. F. de Groot, M. Grioni, J. C. Fuggle, J. Ghijsen, G. A. Sawatzky, and H. Petersen, "Oxygen 1s X-ray-absorption edges of transition-metal oxides," Physical Review B, vol. 40, no. 8, pp. 5715-5723, 1989.

[20] S. Bartkowski, M. Neumann, E. Z. Kurmaev et al., "Electronic structure of titanium monoxide," Physical Review BCondensed Matter and Materials Physics, vol. 56, no. 16, pp. 10656-10667, 1997. 
[21] H. J. Zhai and L. S. Wang, "Probing the electronic structure and band gap evolution of titanium oxide clusters $\left(\mathrm{TiO}_{2}\right)_{n^{-}}(n=1-$ 10) using photoelectron spectroscopy," Journal of the American Chemical Society, vol. 129, no. 10, pp. 3022-3026, 2010.

[22] Y. Gao, Y. Masuda, Z. Peng, T. Yonezawa, and K. Koumoto, "Room temperature deposition of a $\mathrm{TiO}_{2}$ thin film from aqueous peroxotitanate solution," Journal of Materials Chemistry, vol. 13, no. 3, pp. 608-613, 2003.

[23] M. A. Garcia, "Surface plasmons in metallic nanoparticles: fundamentals and applications," Journal of Physics D: Applied Physics, vol. 45, no. 38, Article ID 389501, 2012.

[24] S. Yüzbaş, "A numerical approximation based on the Bessel functions of first kind for solutions of Riccati type differentialdifference equations," Computers \& Mathematics with Applications, vol. 64, no. 6, pp. 1691-1705, 2012.

[25] S. Bosch, J. Ferré-Borrull, N. Leinfellner, and A. Canillas, "Effective dielectric function of mixtures of three or more materials: a numerical procedure for computations," Surface Science, vol. 453, no. 1-3, pp. 9-17, 2000.

[26] T. W. Ebbesen, H. J. Lezec, H. F. Ghaemi, T. Thio, and P. A. Wolff, "Extraordinary optical transmission through sub-wavelenght hole arrays," Nature, vol. 391, no. 6668, pp. 667-669, 1998.

[27] Y. Xie, A. R. Zakharian, J. V. Moloney, and M. Mansuripur, "Transmission of light through slit apertures in metallic films," Optics Express, vol. 12, no. 25, pp. 6106-6121, 2004.

[28] A. K. Sarychev and V. M. Shalaev, "Electromagnetic field fluctuations and optical nonlinearities in metal-dielectric composites," Physics Report, vol. 335, no. 6, pp. 275-371, 2000.

[29] J. B. Pendry, A. J. Holden, D. J. Robbins, and W. J. Stewart, "Low frequency plasmons in thin-wire structures," Journal of Physics Condensed Matter, vol. 10, no. 22, pp. 4785-4809, 1998.

[30] S. A. Ramakrishna, "Physics of negative refractive index materials," Reports on Progress in Physics, vol. 68, no. 2, pp. 449-521, 2005. 

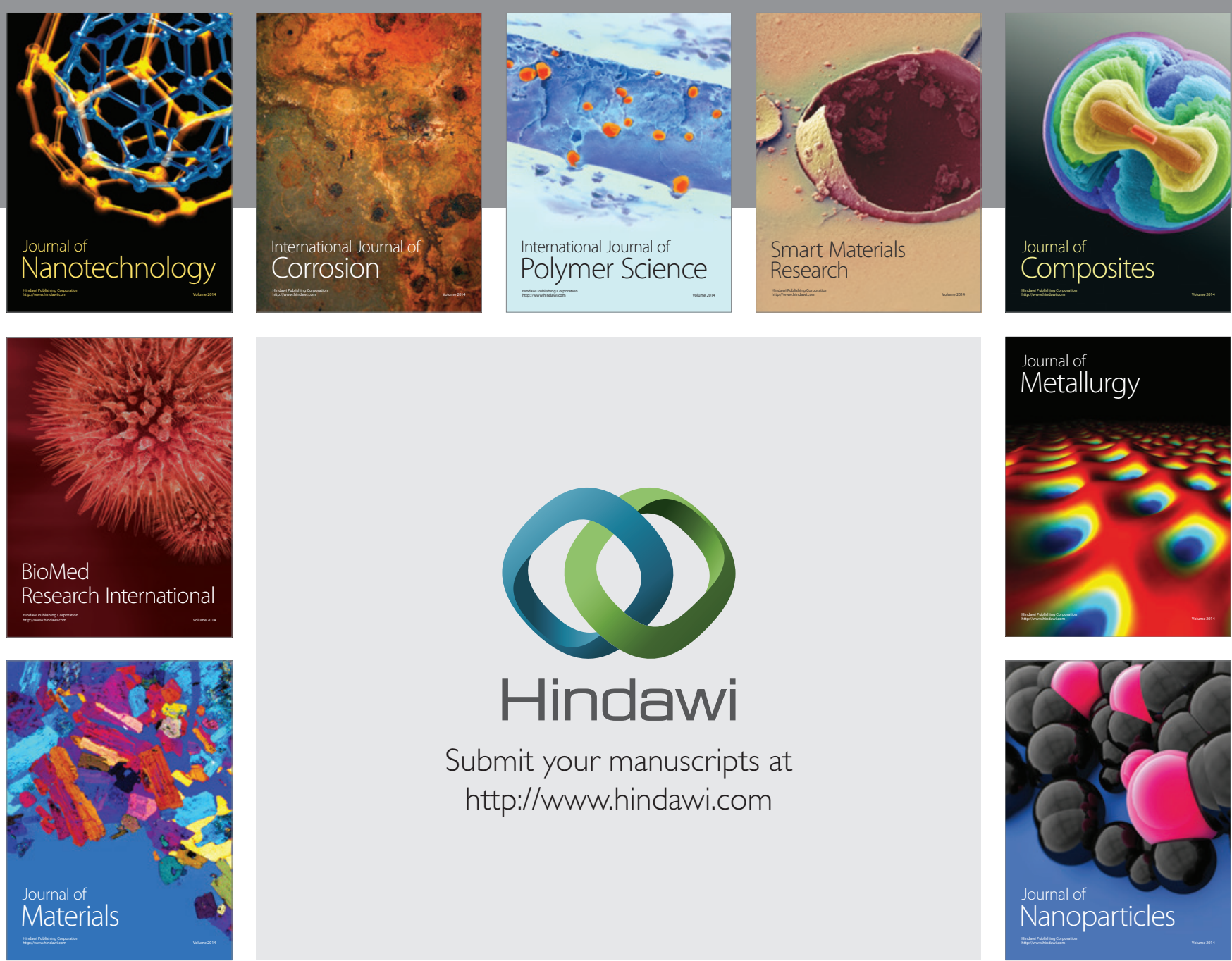

\section{Hindawi}

Submit your manuscripts at

http://www.hindawi.com

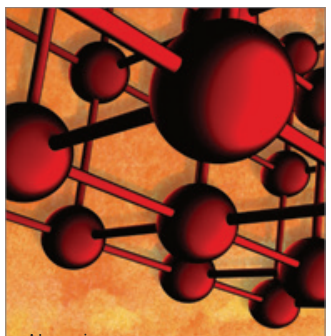

Materials Science and Engineering
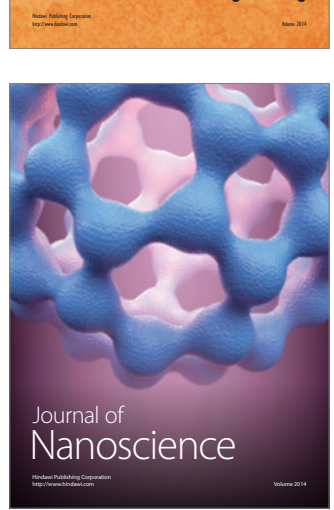
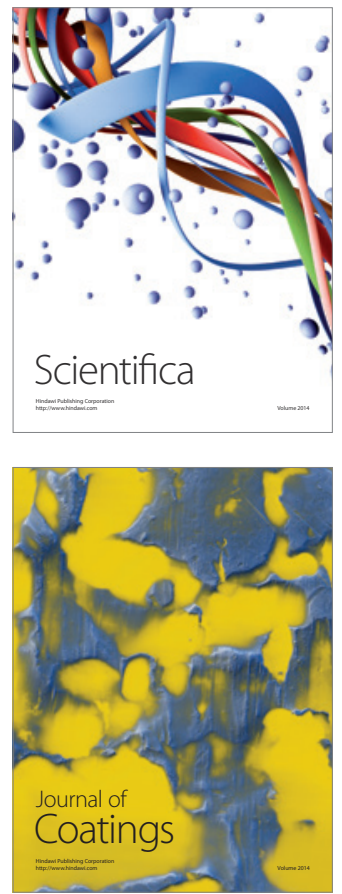
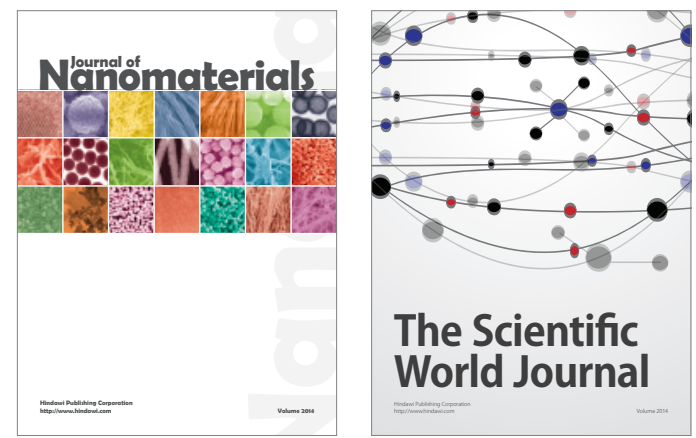

The Scientific World Journal
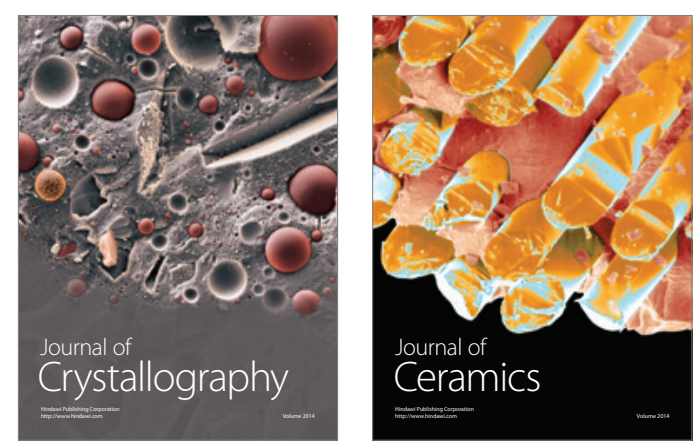
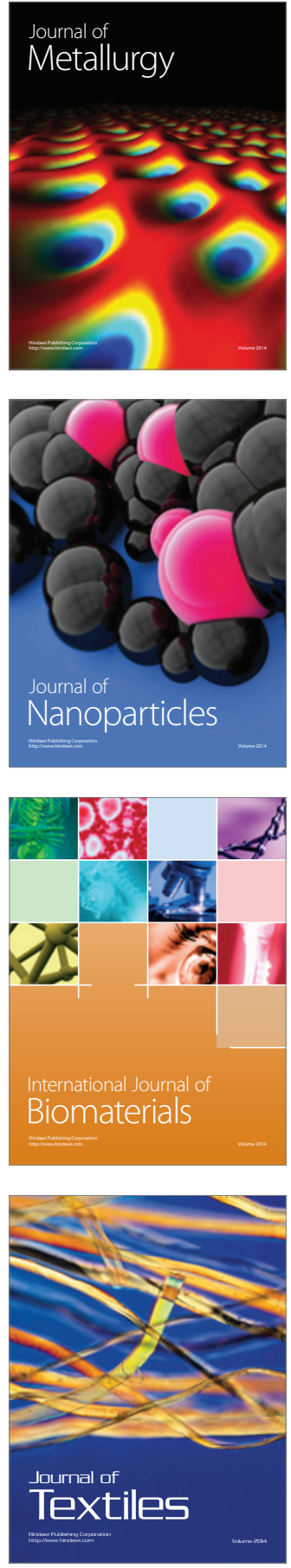